\title{
Aplikasi Persediaan Barang PT. CAD Solusindo Menggunakan Metode Waterfall
}

\author{
Agus Junaidi ${ }^{[1]}$, Candra Sumirat ${ }^{[2]}$ \\ AMIK BSI Jakarta ${ }^{[1]}$, STMIK Nusa Mandiri Jakarta ${ }^{[2]}$ \\ agus.asj@bsi.ac.id ${ }^{[1]}$, candrasumirat21@yahoo.com ${ }^{[2]}$
}

\begin{abstract}
Information technology in company's inventory is essential to support activities of the company. With information technology, process of outgoing and incoming items can be recorded properly, information transmission more quickly and accurately. Until now PT. CAD Solusindo still uses Microsoft Excel program, starting from the receipt of the goods, the goods out and prepare a report addressed to the management. Technical collecting data conducted by observation, interviews and literary studies. Waterfall methods used in this research included requirements analysis system, design, code generation, testing and support. By this solution, the company can be accelerate the inventory items process that still take a long time. These systems are made by using a php application to interface and mysql as the database.
\end{abstract}

Keywords: Information System, Inventory, mysql database

\section{PENDAHULUAN}

Website merupakan salah satu media informasi yang sangat efektif dalam menyajikan informasi, dengan kemajuan teknologi yang semakin pesat serta permintaan akan kebutuhan yang semakin meningkat maka sangat perlu dibutuhkan sistem yang dapat membantu dalam pekerjaan dan juga dalam penyampaian informasi. Adanya jaringan yang luas dan mudah di akses juga merupakan salah satu langkah untuk mendapatkan informasi dengan cepat, maka setiap instansi ingin mengubah sistem yang lama ke sistem yang baru agar tidak tertinggal dengan yang lain.

Perkembangan ilmu pengetahuan dan teknologi dewasa ini telah mendorong manusia pada kehidupan yang lebih baik. Terlebih lagi dengan adanya komputer dimana hal tersebut semakin meningkatkan efesiensi dan kualitas dalam bekerja.dengan adanya komputer,manusia di beri kemudahankemudahan dalam menyelesaikan pekerjaan di berbagai bidang, misalnya bidang perdagangan [1]. Sejak masuknya komputer dalam bidang perdagangan maka aplikasi-aplikasi yang menunjang perdagangan semakin berkembang yang pada akhirnya semakin mempermudah pekerjaan. Informasi merupakan unsur yang mengkaitkan fungsi-fungsi manajemen yang terdiri dari perencanaan, pengoprasian, dan pengendalian perusahaan. Tanpa informasi suatu perusahaan tidak akan bisa menjalankan kegiatan operasional perusahaan dengan baik. Oleh sebab itu untuk menunjang pelaksanaan informasi baik sebuah organisasi, lembaga atau perusahaan yang baik dan teratur, maka diperlukan suatu sistem yang terkomputerisasi.

PT CAD Solusindo adalah perusahaan yang begerak di bidang instalasi dan jasa perbaikan alat-alat telekomunikasi.
Pada proses perbaikan PT CAD Solusindo memerlukan spare part/component, agar kegiatan repair berjalan dengan baik dan lancar. Untuk mempermudah bagian teknisi dalam melakukan pemesanan, dan mempermudah bagian admin/logistik dalam mengelola stok barang/spare part, maka diperlukan pengaturan dengan menerapkan sistem informasi berbasis web untuk menjalankan persediaan barang/spare part dan melakukan pendataan stok barang pada perusahaan. Selama ini sistem persediaan barang/spare part yang ada pada PT CAD Solusindo masih menerapkan sistem semi komputerisasi dimana admin dalam proses penginputan data masih menggunakan Microsoft Excel, dalam proses pencatatan tersebut penggunaan komputer masih kurang optimal sehingga dalam menghasilkan laporan yang akurat dan tepat membutuhkan waktu yang lama sehingga itu dinilai kurang efektif. Jika diuraikan permasalahan tentang persediaan barang pada PT. CAD Solusindo adalah:

a. Kesulitan bagian teknisi dalam melakukan pemesanan spare part.

b. Pencatatan masih kurang maksimal terhadap pendataan persediaan stok barang/spare part yang dimiliki perusahaan.

c. Sulitnya melakukan pengecekan terhadap stok barang/sparepart yang dimiliki perusahaan.

d. Kesulitan dalam membuat laporan karena masih menggunakan Microsoft Excel.

\section{LANDASAN TEORI}

A. Metode Waterfall

Model SDLC atau air terjun (waterfall) sering juga disebut model sekunsial linier (sequential linear) atau alur hidup klasikal (classic life cycle)". Model air terjun menyediakan pendekatan alur hidup perangkat lunak secara sekuensial atau terurut dimulai dari analisis, desain, pengkodean, pengujian dan tahap pendukung /support [2].

B. EntityRelationship Diagram

Model Entity-Relationship yang berisi komponen-komponen Himpunan Entitas dan Himpunan Relasi yang masing-masing dilengkapi dengan atribut-atribut yang mempresentasikan seluruh fakta dari 'dunia nyata' yang kita tinjau, dapat digambarkan dengan menggunakan Diagram EntityRelationship (Diagram E-R) [3].

\section{Persediaan Barang}


Setiap perusahaan memiliki kebutuhan informasi yang berbedabeda untuk meningkatkan produktivitas suatu perusahaan tersebut. Dahulu perusahaan menggunakan program Microsoft Excel untuk menyimpan data-data barang yang masuk dan keluar, permintaan konsumen, ketersedian barang yang ada di gudang. Hal yang menjadi kendala adalah ketika semua informasi tersebut dibutuhkan, maka harus membuka semua tabel yang ada (sheet by sheet). Berdasarkan permasalahan tersebut perlu dibuat sistem informasi yang akurat dan cepat [4]. Penelitian lain tentang Persediaan Barang adalah:

a. Tujuan untuk mengetahui data stok barang serta pembuatan laporannya masih menggunakan cara penulisan di buku, oleh sebab itu banyaknya waktu yang dibutuhkan untuk proses penghasilan laporan yang tepat serta transaksi penjualan barang yang akurat bagi pemilik dan memperbesar kemungkinan kesalahan pencacatan. Sehingga sistem informasi yang dibutuhkan oleh perusahaan ini adalah pembuatan aplikasi dalam pengolahan serta pendataan data persediaan barang (inventory) khususnya persediaan spare part serta laporan yang terkomputerisasi agar pencatatan arus barang masuk servis dan selesai servis dapat secara cepat, tepat, dan akurat [5].

b. Persedian merupakan suatu aktiva yang meliputi barangbarang milik perusahaan dengan maksud untuk dijual dalam suatu periode usaha tertentu atau persediaan barangbarang yang masih dalam pengerjaan yang menunggu penggunaannya dalan suatu perses tertentu. barang, hewan, peristiwa, konsep, huruf, simbol, teks, gambar, bunyi, atau kombinasinya [6].

\section{METODE PENELITIAN}

Metode penelitian merupakan suatu cara bagaimana seorang penulis dapat memahami suatu pokok bahasan, permasalahan dan pemecahan masalah dalam sebuah sistem.

Desain penelitian berisikan pengetahuan, algoritma, metode, produk (sistem), model dan lain sebagainya (Hasibuan, 2007) Dalam peneitian ini penulis melakukan teknik teknik pengumpulan data dengan cara:

1. Observasi

Melalui metode ini penulis melakukan tinjauan langsung pada PT. CAD solusindo untuk mendapatkan informasi tentang profile perusahaan dan data-data yang diperlukan dalam pembuatan skripsi ini.

2. Wawancara

Penulis melakukan tanya jawab langsung kepada bagian teknisi dan beberapa staf karyawan di bagian logistik tersebut, sehingga penulis dapat memperoleh data yang lebih akurat dalam pemecahan masalah yang terjadi pada perusahaan tersebut.

3. Studi Pustaka

Penulis mendapatkan sumber data dari buku, dan jurnaljurnal yang digunakan sebagai referensi dalam penelitian ini, diantaranya:
Dalam proses analisa penelitian, penulis menggunakan metode Waterfall (Pressman, 2010), yaitu meliputi proses:

1. Analisa Kebutuhan sistem

Pada tahap ini dilakukan analisa terhadap sistem yang sedang berjalan dan melakukan pendekatan terhadap kebutuhan-kebutuhan sistem yang baru. Penulis menganalisa kebutuhan apa saja yang dibutuhkan dalam pembuatan sistem informasi persediaan barang berbasis web, diantaranya bentuk dokumen barang masuk, dokumen barang keluar, yang digunakan dalam pembangunan sistem tersebut.

2. Desain

Pada tahap ini penulis melakukan perancangan sistem informasi persediaan barang berbasis web meliputi desain sistem menggunakan Unified Modeling Language, desain database menggunakan ERD, manajemen user, modulmodul pada aplikasi, kontribusi isi program aplikasi dan manajemen database.

3. Code Generation

Code Generation merupakan hasil transfer dari perancangan ke dalam bahasa pemrograman yang telah ditentukan. Desain database menggunakan MYSQL yang di tulis dengan mengunakan bahasa pemrogram Dreamweaver CS6. program yang dibuat dengan menggunakan PHP.

4. Testing

Setelah dilakukan tahap pemrograman, tahap berikutnya yaitu pengujian (testing) sistem secara keseluruhan dari sistem informasi persediaan barang yang telah dibuat. Pengujian dilakukan dengan menggunakan metode pengujian mandiri yaitu dengan cara metode Black Box dengan melakukan tes case. Metode Black dilakukan tanpa melihat source code, program yang di jalankan oleh user untuk mengamati apakah program telah menerima input, memproses, dan menghasilkan output dengan benar.

5. Support

Dalam mendukung aplikasi yang akan dikerjakan diperlukan perangkat keras (hardware), yang menjalankan perangkat lunak (software) dan peralatan ini berfungsi untuk menjalankan instruksi-instruksi yang diberikan dan mengeluarkannya dalam bentuk informasi. Untuk dukungan menjalankan aplikasi yang penulis buat dibutuhkan Dreamweaver CS6, Xampp, MySQL, Dan hardware meliputi : AMD E450, memori 4 GB, Hard Disk 256 GB, Monitor 11.6”, Printer Epson L210.

\section{HASIL DAN PEMBAHASAN}

PT. CAD Solusindo merupakan sebuah perusahaan yang bergerak di bidang jasa perbaikan alat-alat telekomunikasi. PT. CAD Solusindo menjadi kontraktor pelayanan perbaikan untuk semua jenis alat-alat telekomunikasi, melalui komitmen untuk layanan berkualitas tinggi sesuai semua aspek enginering services, sistem integrasi, pasokan bahan serta menyediakan tenaga kerja untuk industri telekomunikasi.

\subsection{Analisa Kebutuhan Software}




\section{A. Tahapan Analis}

Sistem informasi persediaan barang ini berbasis web yang berjalan dijaringan intranet. Berikut ini adalah spesifikasi kebutuhan dari sistem informasi persediaan barang berbasis web:

Halaman Karyawan:

A1. Karyawan harus melakukan login untuk memesan barang.

A2. Karyawan bisa melakukan pemesanan berdasarkan kategori.

A3. Karyawan memilih barang yang akan di pesan, bisa mengecek terlebih dahulu detail produknya.

A4. Karyawan dapat mengecek status pemesanan barang.

A5. Karyawan dapat melihat daftar pesanan.

B. Use Case Diagram

Use Case Diagram dalam perancangan sistem informasi persediaan barang PT. CAD Solusindo adalah sebagai berikut:

1. Use Case Diagram Halaman Karyawan
A6. Karyawan bisa memberikan komentar di testimoni.

Halaman Administrasi :

B1. Admin dapat melakukan login sesuai dengan hak akses.

B2. Admin dapat mengelola data user

B3. Admin dapat mengelola data barang masuk.

B4. Admin dapat mengelola data menu kategori.

B5. Admin dapat mengelola data pesanan

B6. Admin dapat melihat laporan barang masuk.

B7. Admin dapat melihat laporan barang keluar.

B8. Admin dapat mengelola stok barang.

B9. Admin dapat melihat data transaksi.

B10. Admin dapat mengelola testomini.
A7. Karyawan bisa melakukan Logout.

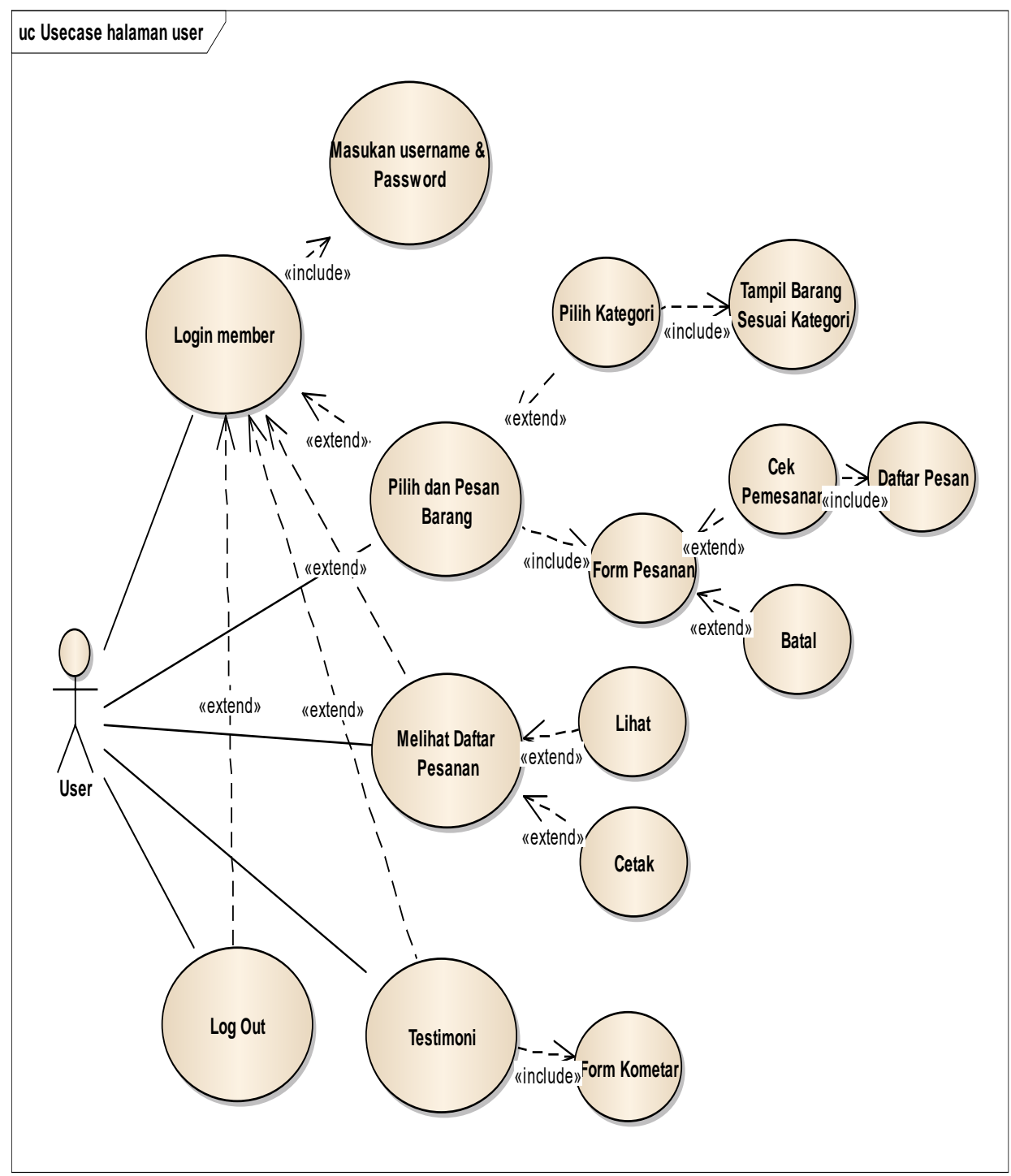

Gambar 1. Use Case Diagram Halaman Karyawan 
2. Use Case Diagram Halaman Admin

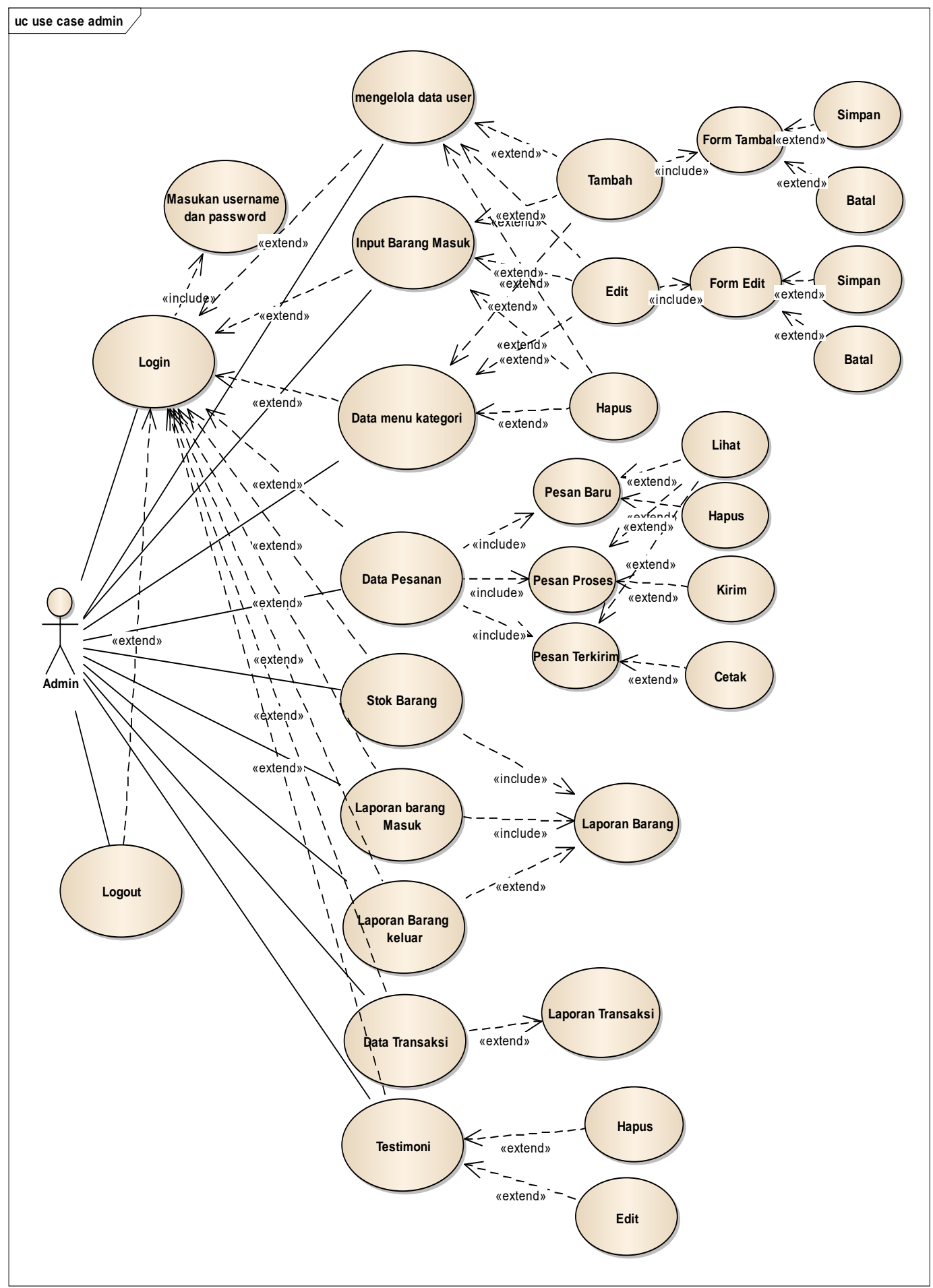

Gambar 2. Use Case Diagram Halaman Admin

\section{Activity Diagram}

Activity diagram menggambarkan berbagai alir aktivitas dalam sistem yang sedang dirancang, bagaimana masing-masing alir berawal, decision yang mungkin terjadi dan bagaimana mereka berakhir.

Berikut ini merupakan desain usulan Diagram Activity persediaan barang PT CAD Solusindo : 
1. Activity Diagram Halaman Karyawan

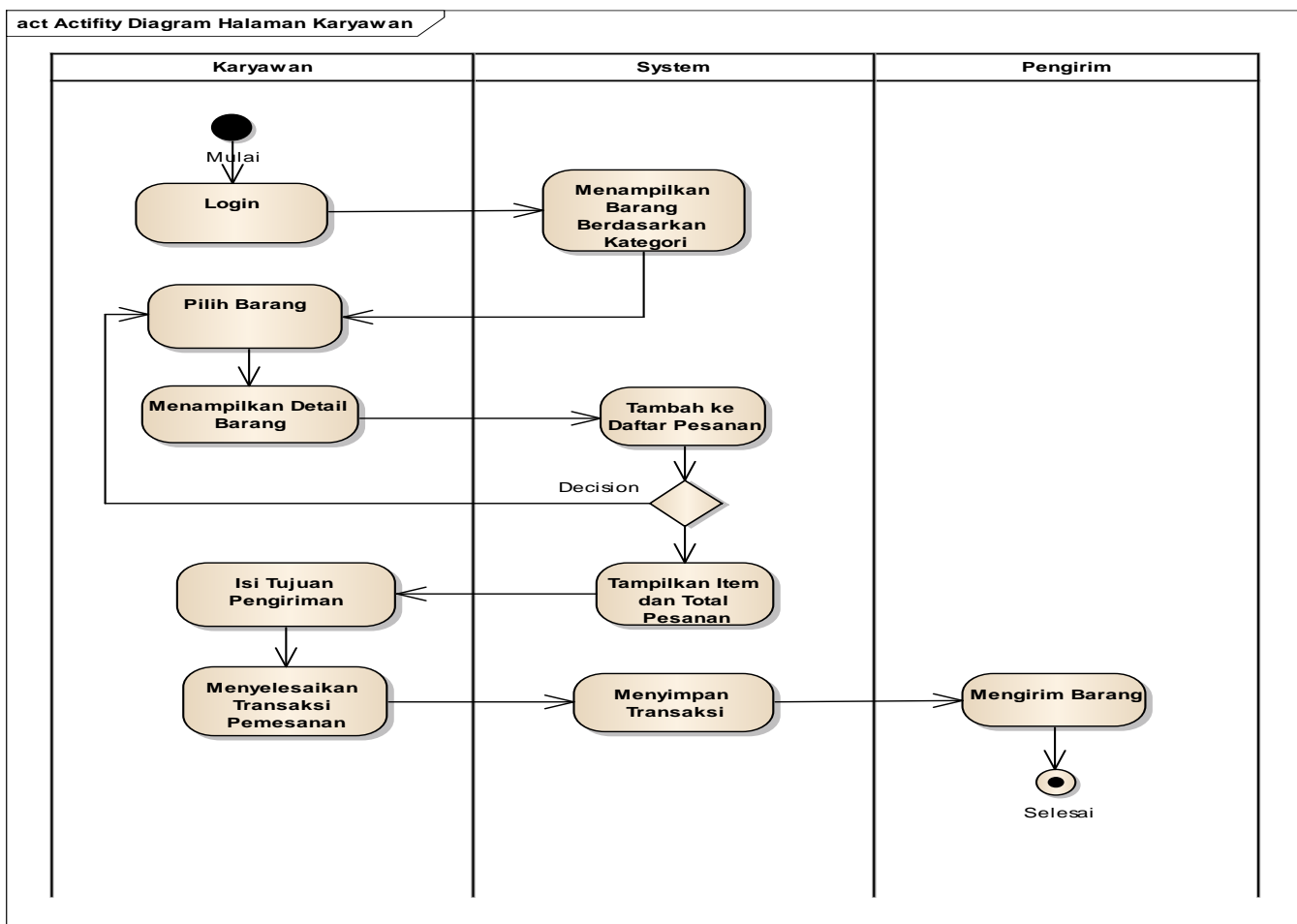

Gambar 3. Activity Diagram Halaman Karyawan

2. Activity Diagram Admin Mengelola Data Admin

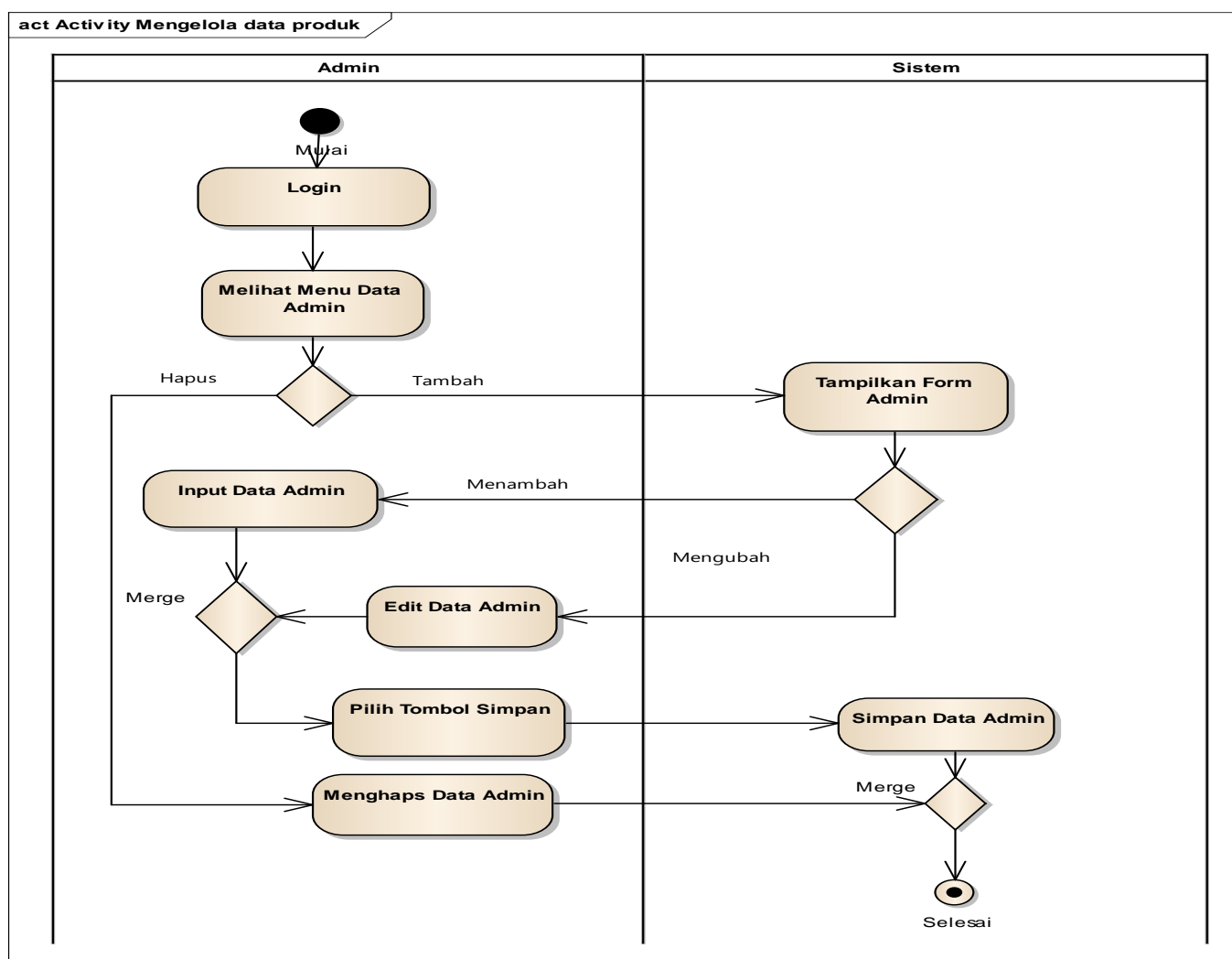

Gambar 4. Activity Diagram Admin Mengelola Data Admin 
3. Activity Diagram Admin Mengelola Data Barang

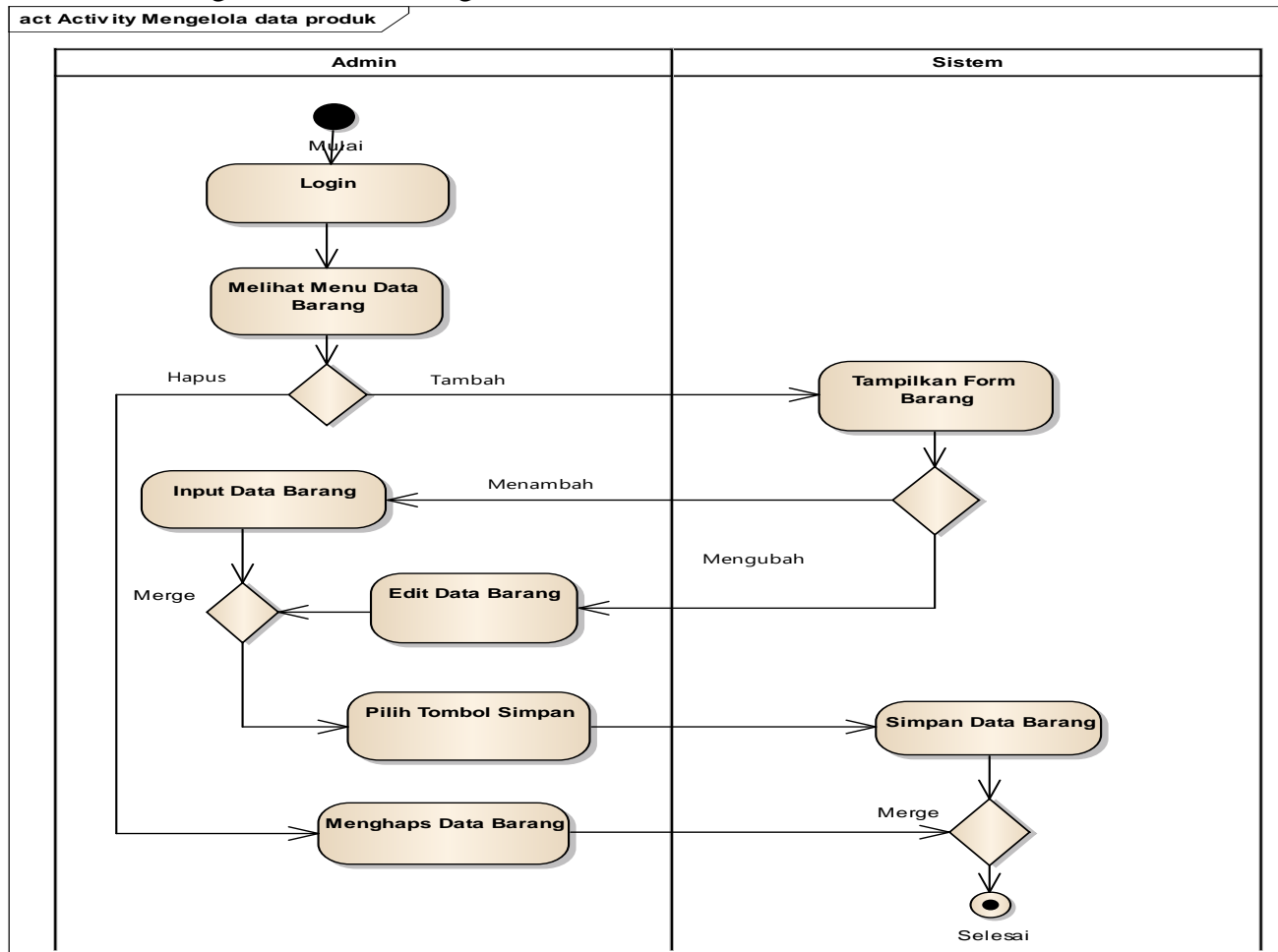

Gambar 5. Activity Diagram Admin Mengelola Data Barang

4. Activity Diagram Admin Mengelola Data Status Pemesanan

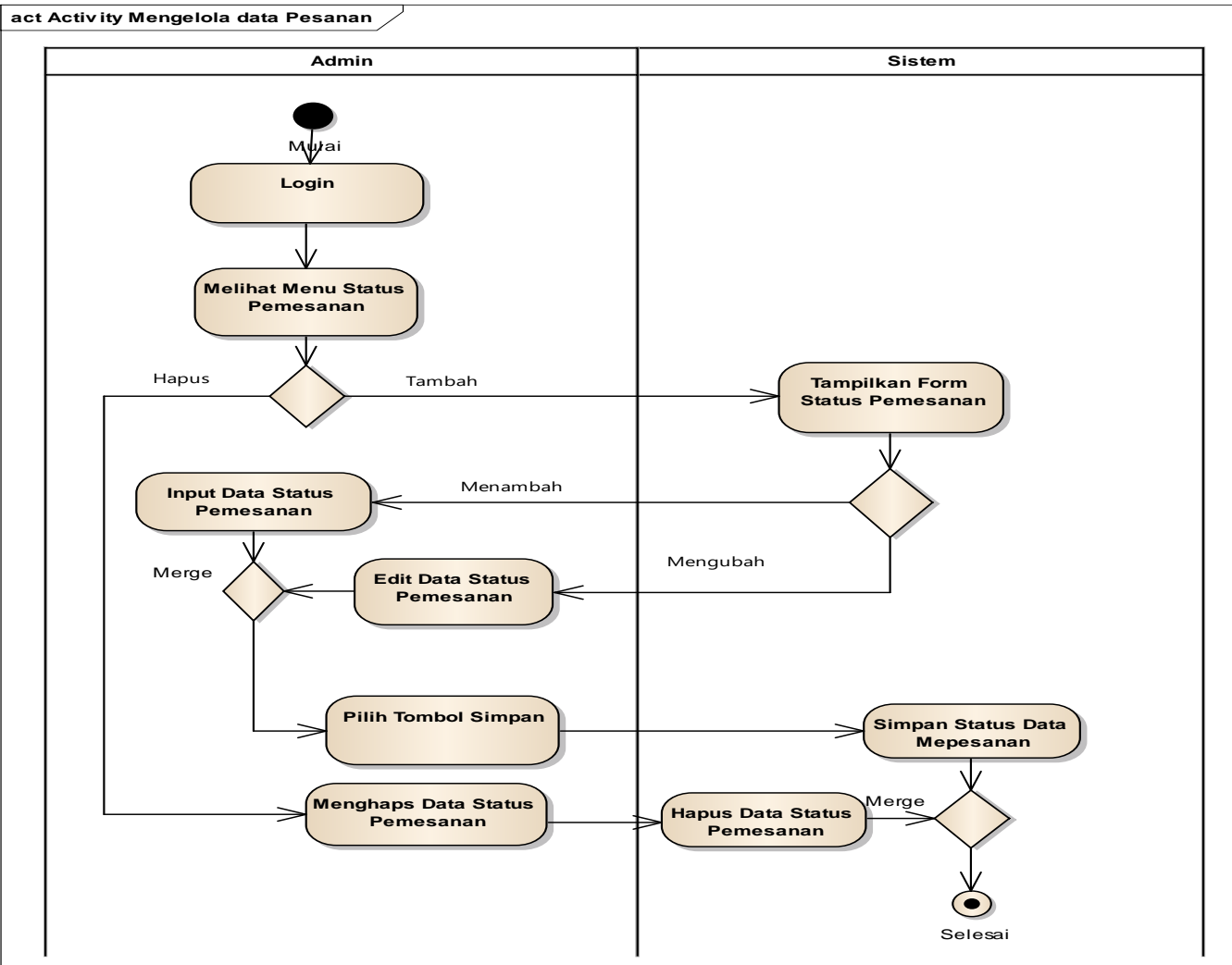

Gambar 6. Activity Diagram Admin Mengelola Data Status Pemesanan 
5. Activity Diagram Admin Mengelola Data Laporan Barang

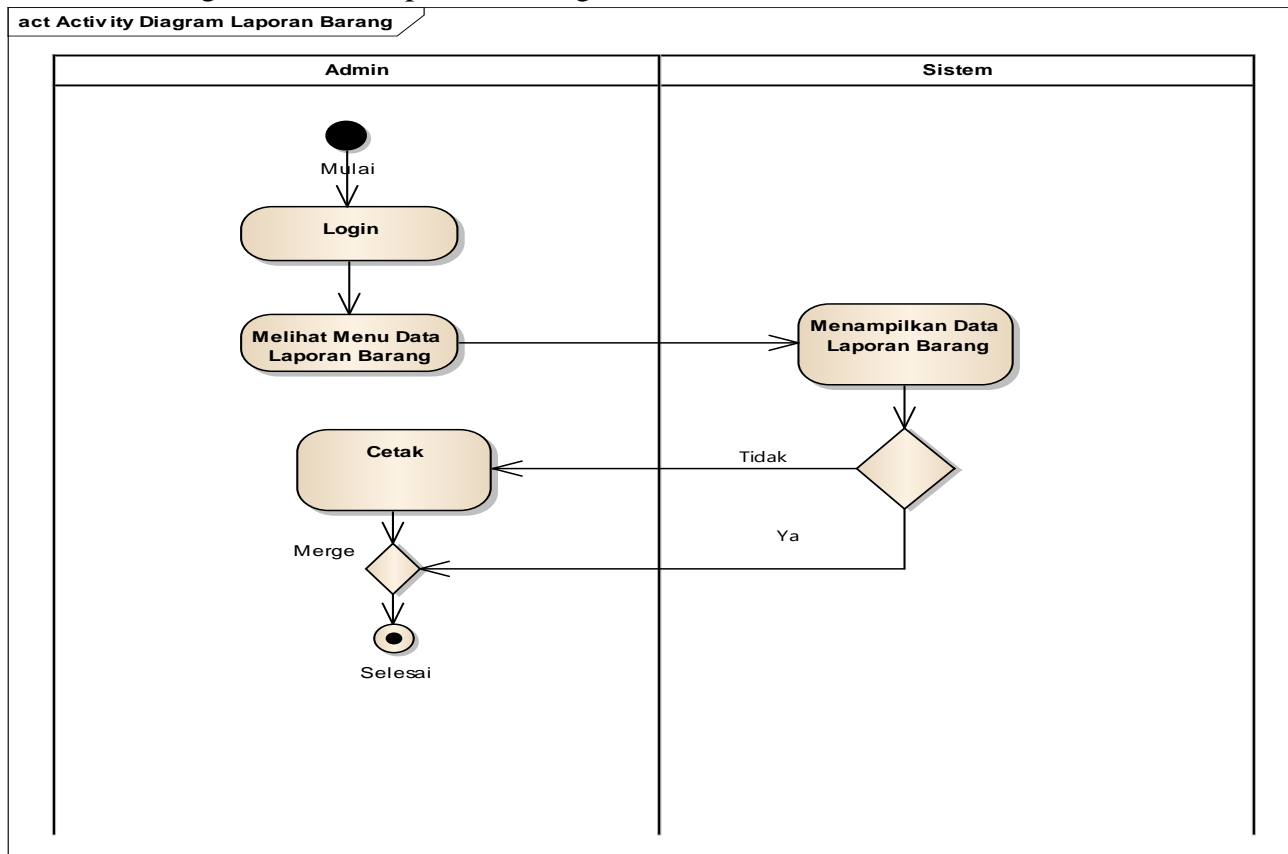

4.2. Desain Database

Gambar 7. Activity Diagram Admin Mengelola Data Laporan Barang

Bentuk ERD ( Entity Relationship Diagram ) yang menggambarkan Model basis data dari sistem yang dibuat adalah sebagai berikut

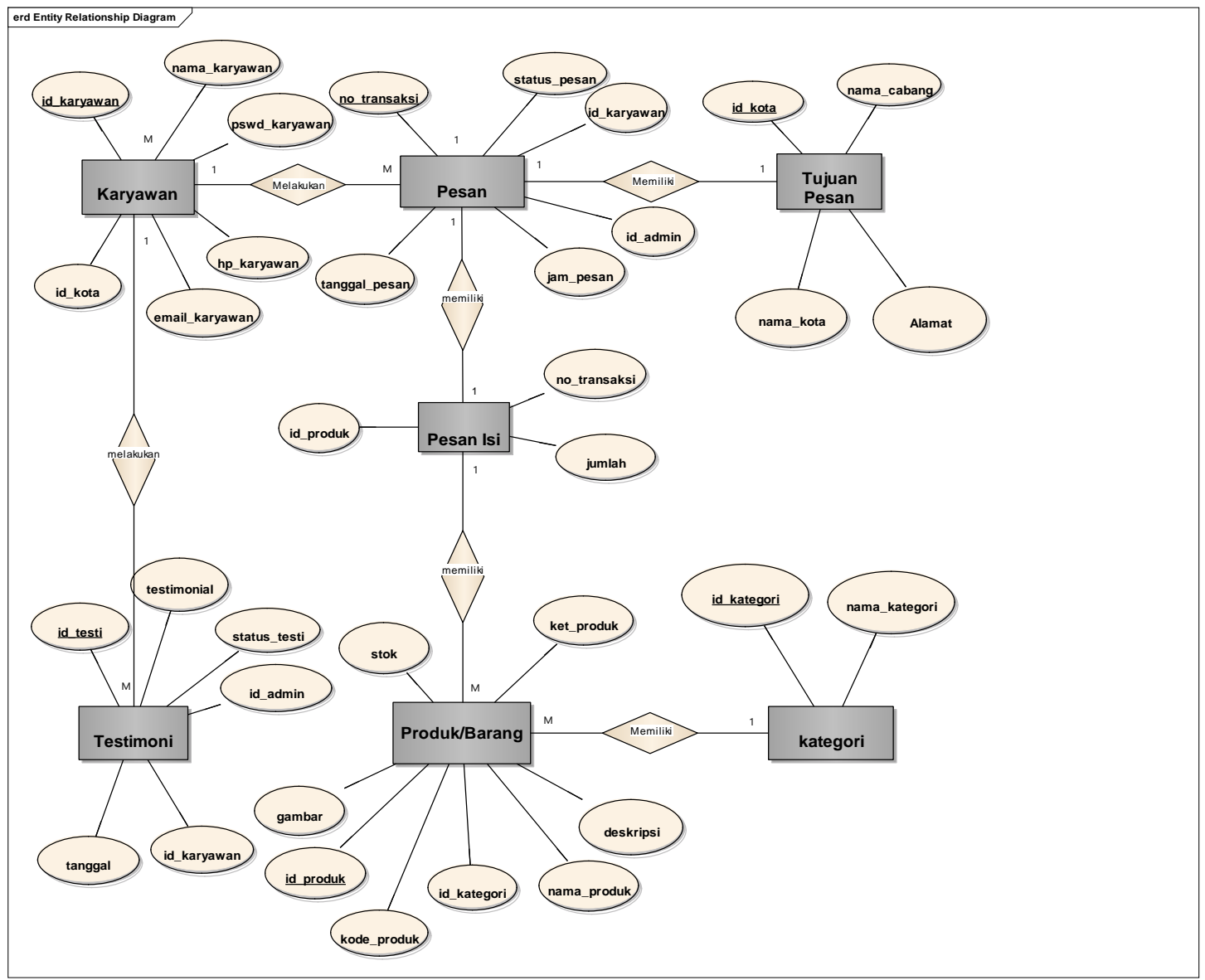

Gambar 8. Entity Relationship Diagram 
4.3. User Interface

a. Tampialn Halaman Login Karyawan

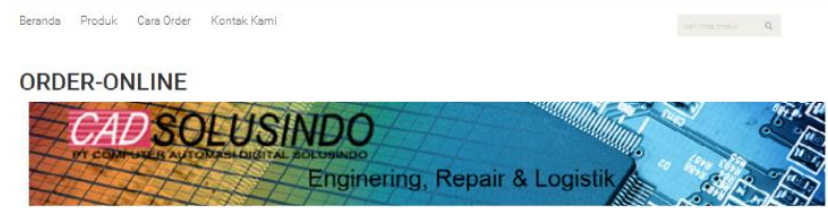

Login-Karyawan

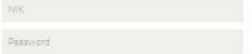

toon.

Gambar 9. Halaman Login Karyawan

b. Tampilan Halaman Home

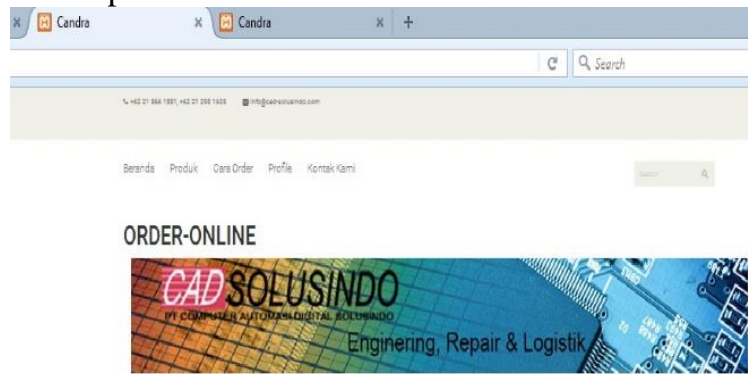

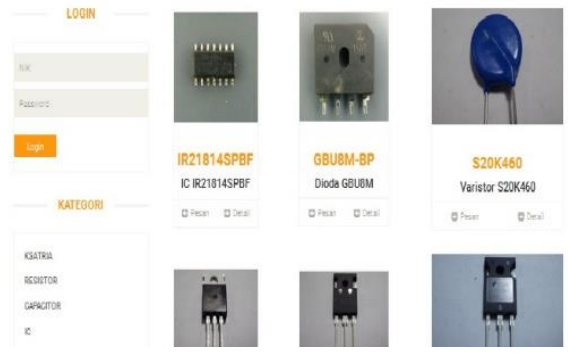

Gambar 10. Halaman Home

c. Tampilan Halaman Login Admin

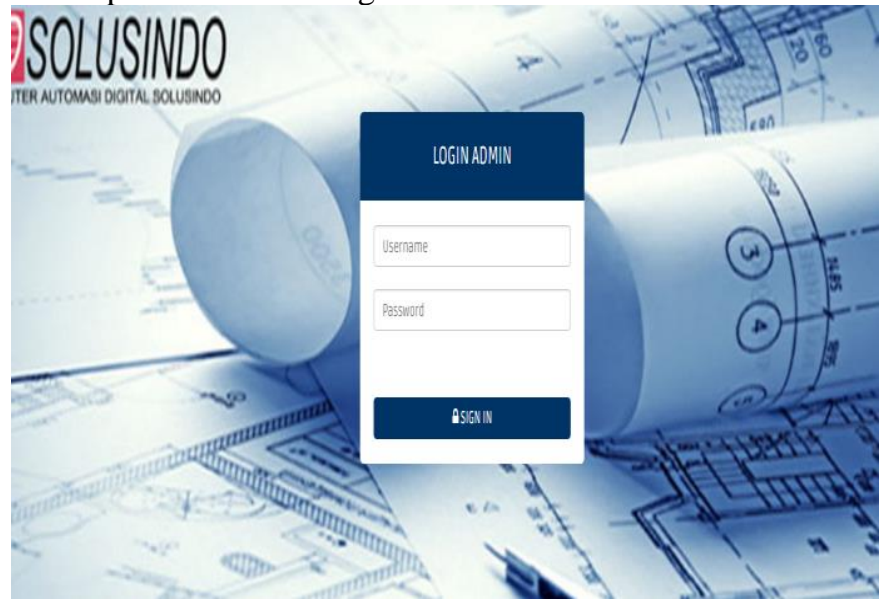

Gambar 11. Halaman Login Admin d. Tampilan Halaman Data Barang

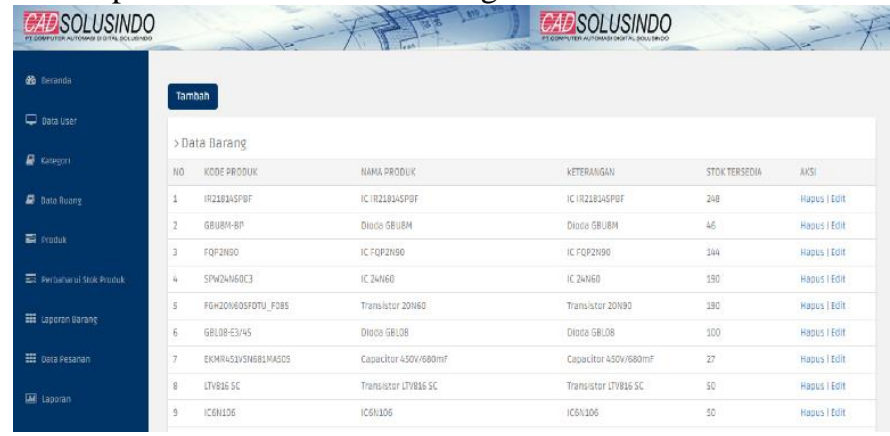

Gambar 12. Daftar barang

e. Tampilan halaman barang keluar/terkirim

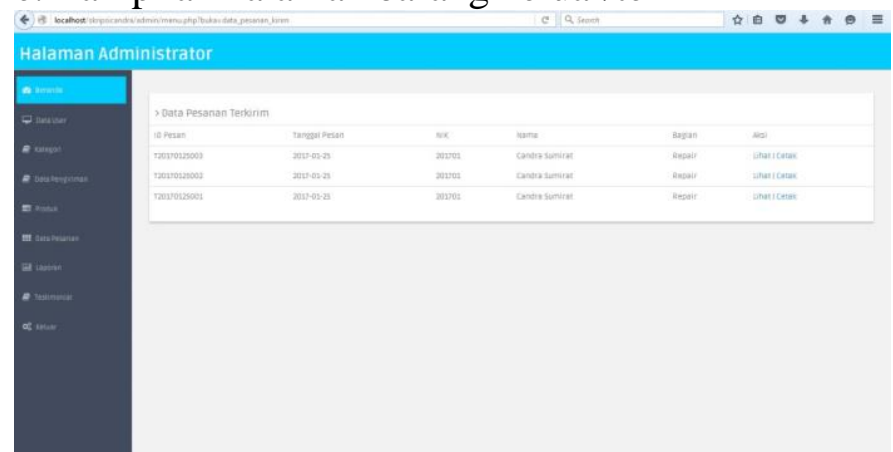

Gambar 13. Halaman barang terkirim

f. Tampilan laporan barang masuk

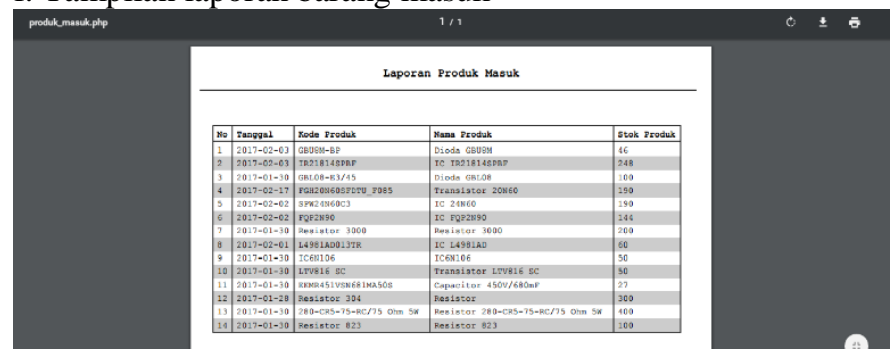

Gambar 14. Laporan barang masuk

\subsection{Code Generation}

Salah satu kode program dalam proses laporan transaksi adalah:

$<$ ?php

session_start();

if (empty(\$_SESSION['idadmin']) AND

empty(\$_SESSION['pswdadmin']))\{

echo " $<$ center $>$ Untuk mengakses halama ini, Anda harus login $<$ br $>$ "; \}

else \{

?)

$<$ ?php

include "class.ezpdf.php",

include "...../konfig/koneksi.php";

$\$ p d f=$ new Cezpdf();

// Set margin dan font

\$pdf->ezSetCmMargins (3, 3, 3, 3);

\$pdf->selectFont('fonts/Courier.afm');

$\$$ all $=\$$ pdf- $>$ openObject ()$;$ 
// Tampilkan logo

\$pdf->setStrokeColor $(0,0,0,1)$;

\$pdf->addJpegFromFile('logo.jpg',20,800,69);

// Teks di tengah atas untuk judul header

\$pdf->addText(195, 810, 13,'<b>Laporan Data Transaksi</b>');

// Garis atas untuk header

\$pdf->line(10, 795, 578, 795);

// Garis bawah untuk footer

\$pdf->line $(10,50,578,50)$

// Teks kiri bawah

//\$pdf->addText(30,34,8,'Dicetak tgl:' . date( 'd-m-Y, H:i:s'));

\$pdf->closeObject();

// Tampilkan object di semua halaman

\$pdf->addObject(\$all, 'all');

\$sql = mysql_query("SELECT * FROM pesan,karyawan,kota where

karyawan.id_karyawan=pesan.id_karyawan and kota.id_kota=pesan.id_kota

and pesan.status_pesan='TERKIRIM' order by tanggal_pesan desc");

$\$ i=1$;

\subsection{Testing}

Salah satu pengujian yang dilakukan menggunakan black box testing pada form tambah data barang adalah

Tabel 1. Pengujian while $(\$ r=$ mysql_fetch_array $(\$ s q l))\{$

$\$$ data[ $\$ \mathrm{i}]=\operatorname{array}(' \mathrm{No}$ ' $=>$ i,

'No Transaksi' $=>$ r[' $[$ notransaksi'],

'Tanggal Pesan'=>\$r['tanggal_pesan'],

'ID Admin' $=>\$ r[$ [id admin'],

'NIK' $=>$ \$r['id_karyawan'],

'Nama'=> \$r['nama_karyawan'],

)

it+;

\$pdf->ezTable(\$data, ', ', , ');

// Penomoran halaman

\$pdf->ezStartPageNumbers $(320,15,8)$;

\$pdf->ezStream();

$<$ ?php \} ?>
'Perusahaan'=> \$r['nama_cabang'],

\begin{tabular}{|c|c|c|c|c|c|}
\hline No & Skenario Pengujian & Test Case & Hasil yang diharapkan & Hasil Pengujian & Kesimpulan \\
\hline 1 & $\begin{array}{l}\text { Mengosongkan semua isian data } \\
\text { form Tambah data Barang. Klik } \\
\text { save }\end{array}$ & $\begin{array}{c}\text { id barang(kosong), nama } \\
\text { barang (kosong), jenis barang } \\
\text { (kosong), harga jual (kosong) }\end{array}$ & $\begin{array}{l}\text { sistem tidak memproses dan } \\
\text { menampilkan pesan "this field is } \\
\text { required (pada kolom yang } \\
\text { kosong)" }\end{array}$ & Sesuai harapan & Valid \\
\hline 2 & $\begin{array}{c}\text { Hanya memasukan data id barang } \\
\text { dan mengosongkan nama barang, } \\
\text { jenis barang dan harga jual, Klik } \\
\text { save }\end{array}$ & $\begin{array}{c}\text { id barang (p01), Nama } \\
\text { barang (kosong), jenis barang } \\
\text { (kosong), harga jual (kosong) }\end{array}$ & $\begin{array}{l}\text { sistem tidak memproses dan } \\
\text { menampilkan pesan "this field is } \\
\text { required (pada kolom yang } \\
\text { kosong)" }\end{array}$ & Sesuai harapan & Valid \\
\hline 3 & $\begin{array}{l}\text { Hanya memasukan data id barang } \\
\text { dan nama barang mengosongkan } \\
\text { jenis barang harga jual, Klik save }\end{array}$ & $\begin{array}{c}\text { id barang (p01), Nama } \\
\text { barang (lq2190), jenis barang } \\
\text { (kosong), harga jual (kosong) }\end{array}$ & $\begin{array}{l}\text { sistem tidak memproses dan } \\
\text { menampilkan pesan "this field is } \\
\text { required (pada kolom yang } \\
\text { kosong)" }\end{array}$ & Sesuai harapan & Valid \\
\hline 4 & $\begin{array}{c}\text { Hanya memasukan data id } \\
\text { barang, nama barang, jenis barang } \\
\text { dan mengosongkan harga jual, } \\
\text { Klik save }\end{array}$ & $\begin{array}{c}\text { id barang (p01), Nama } \\
\text { barang (lq2190), jenis barang } \\
\text { (ptr/printer), harga jual } \\
\text { (kosong) }\end{array}$ & $\begin{array}{l}\text { sistem menyimpan data yang baru } \\
\text { ditambahkan }\end{array}$ & Sesuai Harapan & Valid \\
\hline 5 & $\begin{array}{c}\text { mengisi semua form tambah data } \\
\text { barang tanpa ada kolom isian } \\
\text { yang kosong. Klik save }\end{array}$ & $\begin{array}{c}\text { id barang (p01), Nama } \\
\text { barang (lq2190), jenis barang } \\
\text { (ptr/printer), harga jual } \\
\text { (1500000) }\end{array}$ & $\begin{array}{l}\text { sistem menyimpan data yang baru } \\
\text { ditambahkan }\end{array}$ & Sesuai Harapan & Valid \\
\hline
\end{tabular}

\subsection{Support}

Untuk menjalankan sistem perlu dukungan hardware dan software minimal yang dapat diuraikan sebagai berikut:

\begin{tabular}{|c|c|}
\hline Kebutuhan & Keterangan \\
\hline Sistem Operasi & Windows 7 \\
\hline Processor & Pentium Atom $1.6 \mathrm{~Hz}$ \\
\hline RAM & $4 \mathrm{~GB}$ \\
\hline Harddisk & 256 GB SATA \\
\hline CD-ROM & DVD eksternal \\
\hline Monitor & VIA Chrome 9 \\
\hline Keyboard & Standard \\
\hline Printer & - \\
\hline Mouse & Touchscreen \\
\hline Browser & $\begin{array}{l}\text { Mozilla Firefox, Google } \\
\text { Chrome, Internet Explorer }\end{array}$ \\
\hline Software & $\begin{array}{l}\text { Dreamweaver CS6, } \\
\text { PhpMyAdmin, enterprise } \\
\text { architec, Xampp. }\end{array}$ \\
\hline
\end{tabular}

\section{Tabel 2. Kebutuhan hardware dan software}

\section{A. Kesimpulan \\ V. PENUTUP}

Dari proses analisa sistem, perancangan program hingga tahap implementasi, maka penulis dapat mengambil kesimpulan sebagai berikut:

1. Sistem Informasi inventory yang berbasis web dapat mempermudah dalam membantu aktivitas kegiatan transaksi barang di PT.CAD Solusindo.

2. Sistem pemesanan barang yang berbasis web memberi akses mudah dan cepat bagi user/karyawan untuk memenuhi kebutuhan dalam proses lalu lintas keluar masuknya persediaan barang.

3. Dengan pemakaian sistem yang telah terkomputerisasi dan berbasis web dapat mengurangi kesalahan-kesalahan yang terjadi dalam penginputan barang.

4. Dengan Sistem Informasi persediaan barang yang berbasis web membantu admin/logistik dalam mengontrol stok barang dan persediaan barang. 
5. Penyimpanan data transaksi atau stok barang lebih aman karena berada dalam 1 database yang terintegrasi.

\section{B. Saran}

Dari kesimpulan yang telah diuraikan sebelumnya penulis memberikan saran sebagai berikut:

1. Menjaga hak akses dari sistem yang dibuat dengan menjaga kerahasiaan username dan password user sehingga sistem yang dibuat tidak disalah gunakan oleh pihak yang tidak berkepentingan.

2. Dibutuhkan perawatan terhadap sistem, hal ini bisa dilakukan dengan menjaga pengunaan sistem secara baik dan komunikasi user kepada pembuat sistem bila ditemukan eror saat pengunaan sistem diwaktu mendatang.

3. Bila diperlukan untuk meningkatkan kinerja sistem bisa dikembangkan dan disempurnakan lebih lanjut.

\section{DAFTAR PUSTAKA}

[1] Z. A. Hasibuan, Metodologi Penelitian Pada Bidang Ilmu Komputer Dan Teknologi Informasi. Jakarta: Ilmu Komputer Universitas Indonesia, 2007.

[2] M. Rosa, AS; Shalahuddin, Rekayasa Perangkat Lunak. Bandung: Modula, 2013.

[3] Fatansyah, Basis Data. Bandung: Informatika, 2007.

[4] F. Birtha, Arifudzaki; Soemantri, Maman; Abdian, "Aplikasi Sistem Informasi Persediaan Barang pada Perusahaan Export Hasil Laut Berbasis Web," Transmisi, vol. 12, no. 1, p. 1, 2010.

[5] T. Bustanur Rahmad; Setiadi, "Perancangan sistem informasi inventory spare part elektronik berbasis web php.," J. Sarj. Tek. Inform., vol. 2, no. 2, 2014.

[6] Y. Liza and Yupinti, "Sistem Informasi persediaan barang pada PT.Surya Nusa Bhaktindo Bengkulu," Media Infotama, vol. 8, no. 1, pp. 90-117, 2012. 